\title{
The Threshold Effect of FDI Spillover Absorption and Proportion of Employment in Tertiary Industry
}

\author{
XIAO LEI \\ School of Information Management \\ Beijing Information Science and Technology University \\ Beijing, 100192, China
}

\begin{abstract}
Based on the provincial panel data from 2008 to 2017, the Hansen threshold regression model is constructed to empirically test the threshold effect of FDI spillover and the proportion of employment in tertiary industry. The research shows that FDI spillover has a double threshold effect based on the proportion of tertiary industry employment. When the threshold value is lower than the first threshold, it shows a negative effect; the higher the employment proportion of the tertiary industry, the more significant positive effect of the spillover; human capital and research and development stock are two other important factors to promote regional technology level. Both eastern and western regions have FDI spillover threshold effect based on the proportion of employment in the tertiary industry. FDI spillover threshold effect based on the proportion of the tertiary industry employment exists in the east, the middle and the west. Wherein, the east has the highest threshold and the most significant promotion effect, while the west has the lowest threshold and has a restraining effect on the local technical level.
\end{abstract}

Keywords-Threshold regression; FDI spillover; The proportion of employment; Tertiary industry

\section{INTRODUCTION}

Spillover effects of foreign direct investment (FDI) research began in the $1960 \mathrm{~s}$, MacDougall (1960) first proposed the spillover effects of FDI, and thinks that in the process of foreign direct investment is often accompanied by the spread of technology, and concentrated reflection for multinational companies to enter the host countries "economic externality" of the enterprise [1]. With the development of endogenous economic growth theory and the systematization of knowledge spillover theory, FDI began to be widely studied as an important way of technology spillover.

Kokko(1994) first studied the comprehensive effect of FDI spillover, and believed that the it was a comprehensive reflection of demonstration effect, correlation effect, training effect and competition effect. As the competition effect has two sides, FDI spillover is often found to have a negative effect on the economic growth of host countries[2]. Harrison(1994)called the negative effect "crowd-out effect" when studying the effect of FDI on domestic enterprises[3]. Jin(2011)established the spillover endogenous growth model of three-sector FDI with multiple parameters, and the research shows that when the growth rate of foreign human capital is higher than that of host country, FDI could promote the economic growth of host country[4]. The research on technological progress and technological innovation by FDI spillover has been controversial in academic circles Javorcik(2003) studied the industrial panel data of Lithuania from 1996 to 2000 and found that the backward correlation between industries was positively correlated with productivity, while the forward correlation did not find this positive spillover effect[5]. Jiang (2005) analyzed the industry panel data from 1998 to 2002, and found that FDI's competitive effect was not conducive to the growth of domestic enterprises' innovation ability, but promoted domestic enterprises' research and development activities through demonstration effect and the flow of scientific and technological personnel [6].

The differences in empirical results lead to the thinking of the academic circle on the influencing factors of FDI absorption. Borensztein (1998) uses human capital as the factors affecting the absorption capacity of the host country's absorptive capacity concrete quantification, design for the endogenous growth model which contains both human capital and FDI, and the results indicate that FDI is combined with the host country of the human capital stock plays an significant role in economic growth. At the same time, FDI's technology spillover effect has a "critical level", and only when the host country's human capital stock is sufficient, the host country's economy can absorb FDI's technology spillover [7].

However, there is some subjectivity in the cross term test, and the significance and correctness of the critical value cannot be tested. Hansen $(1996,1999)$ proposed the panel data threshold regression model, which does not need to be given the form of nonlinear equation, and the number of threshold values was determined by the number of samples, and provided the confidence interval of the parameters to be estimated[8-9].

\section{MODEL CONSTRUCTION AND ANALYSIS}

This paper mainly examines the technology spillover in FDI spillover, and the effect of R\&D and FDI on productivity often has a time lag, so it takes a lag of one stage variable and establishes a basic model such as formula (1),

$$
\begin{aligned}
\ln t f p_{i t}= & \alpha+\beta \ln H_{i t}+\lambda \ln R_{i t-1} \\
& +\theta \ln F D I_{i t-1}+u_{i t}
\end{aligned}
$$

$i$ is the province, $t$ is year, $t f p$ is technical level, $H$ is regional human capital, $R$ is regional $\mathrm{R} \& \mathrm{D}$ capacity, $F D I$ is foreign direct investment level, $\alpha$ is the intercept term, $u$ represents the random disturbance term. 
The catalogue of guidance for foreign-invested industries clearly proposes to guide foreign investment in service, logistics and other tertiary industries so as to increase the proportion of employment in the tertiary industry in the total employment of the whole country. Therefore, this paper takes the proportion of employment in the tertiary industry as the threshold variable, and according to Hansen threshold regression model, a double threshold model is established, as shown in formula (2); $C Y$ is the threshold variable, $c y$ is the threshold value.

$$
\begin{aligned}
\ln t f p_{i t}= & \alpha+\beta \ln H_{i t}+\lambda \ln R_{i t-1} \\
& +\theta_{1} \ln F D I_{i t-1} * I\left(C Y_{i t} \leq c y_{1}\right) \\
& +\theta_{2} \ln F D I_{i t-1} * I\left(C Y_{i t}>c y_{1}\right)+u_{i t} \\
\ln t f p_{i t}= & \alpha+\beta \ln H_{i t}+\lambda \ln R_{i t-1} \\
& +\theta_{1} \ln F D I_{i t-1} * I\left(C Y_{i t} \leq c y_{1}\right) \\
& +\theta_{2} \ln F D I_{i t-1} * I\left(c y_{1}<C Y_{i t} \leq c y_{2}\right) \\
& +\theta_{3} \ln F D I_{i t-1} * I\left(C Y_{i t}>c y_{2}\right)+u_{i t}
\end{aligned}
$$

Articles intercepted 2008 2017 year to be observed, selected China's 30 provinces except Tibet, Hong Kong, Macao and Taiwan.

The Malmquist index based on DEA method was used to measure regional total factor productivity as technical level. The base period was selected in 2008, measured by the regional output, labor force and capital stock. Regional R\&D capacity adopts the perpetual inventory method of R\&D investment to calculate, and the depreciation rate is $15 \%$. Human capital is calculated by education years per capita. FDI level is calculated by the proportion of FDI stock in GDP, and the inventory of FDI stock is calculated by the method of sustainable inventory, with the depreciation rate of $15 \%$.The proportion of the number of people employed in the tertiary industry is calculated based on the proportion of the number of people employed in the tertiary industry in the total number of people employed in the region

The data sources mainly include: China statistical yearbook; China science and technology statistical yearbook. All monetary measurements are converted to 2008 constant prices in millions of dollars.

\begin{tabular}{cccc}
\hline Pedroni test & Panel V & Panel Rho & Panel PP \\
& $-4.765(0.000)$ & $-5.671(0.000)$ & $-6.178(0.000)$ \\
& & & \\
\hline & Group Rho & Group PP & Panel ADF \\
& $-7.318(0.000)$ & $-15.011(0.000)$ & $-8.185(0.000)$ \\
\hline Kao test & ADF & & \\
& $-10.825(0.000)$ & & \\
&
\end{tabular}

$-10.825(0.000)$

\section{EMPIRICAL RESULTS}

Results of LLC test, Breitung test, IPS test, Fisher ADF, Fisher PP test showed that the variable passed the usual significance test $(1 \%, 5 \%$ and $10 \%)$, proving that the panel data sequence was stable. The Pedroni test was then performed as in TABLE II:

TABLE I CO-INTEGRATION RELATIONSHIP TEST RESULTS

$P$ value is shown in parentheses

Panel ADF and other tests all reject the null hypothesis of 'no co-integration relationship' at the significance level of $1 \%$, indicating the existence of co-integration relationship between variables, which can be used for Panel data regression analysis.

According to the model test method and variable measure introduced above, this paper uses Stata12.0 to conduct single threshold, double threshold and multiple threshold tests on the model in turn. The number of "self-sampling" is 500 times..

TABLE II THRESHOLD TEST RESULTS, THRESHOLD VALUES AND CONFIDENCE INTERVALS

\begin{tabular}{ccccc}
\hline & F Value & P Value & $\begin{array}{c}\text { Threshold } \\
\text { value }\end{array}$ & $\begin{array}{c}\text { Confidence } \\
\text { intervals }\end{array}$ \\
\hline $\begin{array}{c}\text { Single } \\
\text { threshold } \\
\text { Double } \\
\text { threshold } \\
\text { Triple } \\
\text { threshold }\end{array}$ & 16.477 & 0.000 & 0.340 & {$[0.321,0.358]$} \\
\hline
\end{tabular}

The employment proportion of the tertiary industry has a double threshold effect on FDI spillover absorption, which is significant at the $1 \%$ level. Confidence interval of threshold model is determined according to likelihood ratio statistics, as shown in TABLE II. The threshold values of the two-threshold model are 0.340 and 0.445 respectively. 
TABLE III

PLS AND HANSEN REGRESSION RESULTS

\begin{tabular}{cccc}
\hline Variable & Coefficient & Standard Deviation & P Value \\
\hline $\ln H_{i t}$ & $0.317^{* * *}$ & 0.104 & 0.000 \\
$\ln R_{i t-1}$ & $0.234^{* * *}$ & 0.097 & 0.000 \\
$\ln \left(F D I_{i t-1}\right)^{*}$ & & & 0.000 \\
$I\left(C Y_{i t} \leq c y_{1}\right)$ & $-0.090^{* * *}$ & 0.017 & 0.022 \\
$\ln \left(F D I_{i t-1}\right)^{*}$ & $0.085^{* *}$ & 0.013 & 0.003 \\
$I\left(c y_{1}<C Y_{i t} \leq c y_{2}\right)$ & & 0.044 & \\
$\ln \left(F D I_{i t-1}\right)^{*}$ & $0.118^{* * *}$ & & 0.672 \\
$I\left(C Y_{i t}>c y_{2}\right)$ & & 20.741 & \\
$R^{2}$ & & $* *, * *$ significance at a 5 and $1 \%$ level, respectively
\end{tabular}

According to the regression results, R-squared of the model reached $67.2 \%$, indicating that the model variables were reasonable and scientific, as shown in TABLE III.

Human capital and R\&D stock have significant promoting effects on technology level, and the elasticity is 0.317 and 0.234 respectively (significance at $1 \%$ level). FDI spillover has a significant threshold effect based on the proportion of people employed in the tertiary industry. When the threshold variable is lower than the first threshold value of 0.340 , the elasticity is -0.090 , and the spillover has a negative effect on the technical level; when the threshold variable is in the interval [0.340, $0.445]$, the elasticity is 0.085 , showing a promoting effect; when the threshold variable is higher than the second threshold value of 0.445 , the elasticity is 0.118 , further enhancing the promotion effect.

The research results show that human capital and R\&D stock are the most important driving forces for technology upgrading, while FDI spillover shows regional heterogeneity. Spillover only shows a positive effect when the proportion of high-tech industry employees reaches a certain level. With the increase of the proportion of employees in high-tech industry, the marginal effect of spillover elasticity increases.

TABLE IV THRESHOLD TEST RESULTS IN THE EAST, MIDDLE AND WEST

\begin{tabular}{cccc}
\hline & East & Middle & West \\
\hline Single threshold & 0.388 & 0.336 & 0.296 \\
Confidence & {$[0.470$,} & {$[0.286$,} & {$[0.325$,} \\
intervals & $0.508]$ & $0.427]$ & $0.339]$ \\
Double threshold & $/$ & $/$ & $/$ \\
Confidence & & & $/$ \\
intervals & $/$ & $/$ &
\end{tabular}

According to the division of administrative regions in China, the samples are divided into three parts: east, middle and west, and the single threshold, double threshold and multiple threshold tests are conducted successively.
As shown in TABLE IV, East, middle and west all passed the single threshold test and failed the double threshold test. The threshold value of east is 0.388 , higher than the first threshold value of 0.340 , indicating that the "trigger point" of positive FDI spillover effect in the east is relatively high. The threshold value in the middle is 0.336 , almost the same as the first threshold in China. The threshold value of west is 0.296 , lower than the national level.

TABLE V THRESHOLD REGRESSION RESULTS IN THE EAST, MIDDLE AND WEST

\begin{tabular}{cccc}
\hline Variable & East & Middle & West \\
\hline $\ln H_{i t}$ & $0.334^{* * *}$ & $0.267^{* *}$ & $0.274^{* * *}$ \\
$\ln R_{i t-1}$ & $(5.992)$ & $(2.561)$ & $(4.123)$ \\
$\ln \left(F D I_{i t-1}\right) *$ & $(4.329)$ & $(8.273)$ & $(4.731)$ \\
$I\left(C Y_{i t} \leq c y_{1}\right)$ & $0.096^{* * *}$ & $-0.046^{* * *}$ & $-0.112^{* * *}$ \\
$\ln \left(F D I_{i t-1}\right) *$ & $(3.907)$ & $(-3.499)$ & $(-5.959)$ \\
$I\left(C Y_{i t}>c y_{1}\right)$ & & & \\
$c y_{1}$ & $(2.371)$ & $(4.187)$ & $(1.574)$ \\
& & & $0.065^{* * *}$ \\
\end{tabular}

In the east, when the proportion of employment in the tertiary industry is lower than the threshold value, the elasticity is 0.096 ; When the threshold value is higher, the elasticity is 0.125 , indicating that FDI spillover in the east has played a decisive role in technological progress.

In the middle, when the proportion of value-added of the tertiary industry is lower than the threshold value, the elasticity is -0.046 ; When higher than the threshold value, the elasticity is 0.065 , indicating that the proportion of employment in the tertiary industry has a certain promoting effect on FDI spillover.

On both sides of the threshold value in the west, FDI spillover presents a negative effect, with elasticity of -0.112 and -0.063 , respectively. Therefore, for the west, the proportion of employment in the tertiary industry limits the positive spillover effect of FDI and hinders local technology catch-up. 


\section{CONCLUSION}

The empirical analysis of the third industry employment proportion influence on FDI technology spillover effect by Hansen threshold panel model. Studies have shown that in addition to the stock of human capital and R\&D, FDI spillover is a driving force of regional technology development potential, but influenced by regional employment proportion of tertiary industry, and the higher proportion of, spillover effect is more significant.

East, middle and west all have FDI spillover threshold effect based on the proportion of tertiary industry employment. The east has the highest threshold value and the most obvious FDI spillover effect; FDI spillover effect is positive only when the threshold value is exceeded in the middle; the threshold value in the west is the lowest, but FDI spillover is always realized as a restraining effect on regional technological progress.

\section{ACKNOWLEDGMENT}

This research was financially supported by the National Science Foundation of China (NO. 70973011) and Science and Technology Projects of Beijing Municipal Education Commission(NO.SM201811232003). The authors also gratefully acknowledge the helpful comments and suggestions of the reviewers, which have improved the presentation.

\section{REFERENCES}

[1] MacDougall G. The Benefits and Costs of Private Investment from Abroad: A Theoretical Approach[J]. Economic Record, 1960(36): 13-35.

[2] Kokko, A. Technology, Market Characteristics, and Spillovers[J]. Journal of Development Economics, 1994, 43(2): 279-293.

[3] Harrison, A. Productivity, Imperfect Competition and Trade Reform[J]. Journal of International Economies, 1994(36):53-73.

[4] Jin N, Fu Q. Endogenous Growth Model of Multi-Parameter FDI Spillover and its Simulation[J].Soft Science,2011,25(6):140-144.

[5] Javorcik, B.S., Spatareanu, M. To Share or Not to Share: Does Local Participation Matter for Spillover from Foreign Direct Investment?[R]. Policy Research Working Paper Series 3118, The World Bank, 2003.

[6] Jiang D, Xia L. The Empirical Study of the Function of FDI on Innovation in China's High-Tech Industries[J].World Economy, 2005(8):3-11.

[7] Borensztein. E, Gregorio J.d and Lee J-w. How Does Foreign Direct Investment Affect Economic Growth?[J]. Journal of International Economics, 1998(45): 115-135.

[8] Hansen, B.E. Inference When a Nuisance Parameter Is Not Identified under the Null Hypothesis [J]. Econometrica, 1996, 64(2):413-430.

[9] Hansen, B.E.1999.Threshold effects in non-dynamic panels: Estimation, testing, and inference [J].Journal of Econometrics, 1999, 93(2):345-368. 